\title{
Optimization of triple-alternating-gas (TAG) injection technique for enhanced oil recovery in tight oil reservoirs
}

\author{
Mvomo Ndzinga Edouard ${ }^{1,2} \cdot$ Pingchuan Dong ${ }^{1,2} \cdot$ Chinedu J. Okere $^{1} \cdot$ Luc Y. Nkok $^{1,2} \cdot$ Abakar Y. Adoum $^{1,2}$. \\ Nguu D. muchiri ${ }^{1}$. Gao Xiaodong ${ }^{1,2} \cdot$ Fame N. Jacques $^{3}$. Samba K. Prosper ${ }^{3}$
}

Received: 28 July 2021 / Accepted: 1 November 2021 / Published online: 21 November 2021

(C) The Author(s) 2021

\begin{abstract}
After single-gas (SG) injection operations in tight oil reservoirs, a significant amount of oil is still unrecovered. To increase productivity, several sequencing gas injection techniques have been utilized. Given the scarcity of research on multiple-gas alternating injection schemes, this study propose an optimized triple-alternating-gas (TAG) injection for improved oil recovery. The performance of the TAG process was demonstrated through numerical simulations and comparative analysis. First, a reservoir compositional model is developed to establish the properties and composition of the tight oil reservoir; then, a suitable combination for the SG, double alternating gas (DAG), and TAG was selected via a comparative simulation process. Second, the TAG process was optimized and the best case parameters were derived. Finally, based on the oil recovery factors and sweep efficiencies, a comparative simulation for SG, DAG, and TAG was performed and the mechanisms explained. The following findings were made: (1) The DAG and TAG provided a higher recovery factor than the SG injection and based on recovery factor and economic advantages, $\mathrm{CO}_{2}+\mathrm{CH}_{4}+\mathrm{H}_{2} \mathrm{~S}$ was the best choice for the TAG process. (2) The results of the sensitivity analysis showed that the critical optimization factors for a TAG injection scheme are the injection and the production pressures. (3) After optimization, the recovery factor and sweep efficiency of the TAG injection scheme were the best. This study promotes the understanding of multiple-gas injection enhanced oil recovery (EOR) and serves as a guide to field design of gas EOR techniques.
\end{abstract}

Keywords EOR · Triple-alternating-gas injection · Oil recovery factor $\cdot$ Sensitivity analysis $\cdot$ Tight oil reservoirs

$\begin{array}{ll}\text { Abbreviations } \\ \text { API } & \text { American Petroleum Institute } \\ \text { CMG } & \text { Computer Management Group } \\ \text { COP 21 } & \text { Paris Climate Conference 2015 } \\ \text { EOR } & \text { Enhanced oil recovery } \\ \text { EOS } & \text { Equation of state } \\ \text { DAG } & \text { Double alternating gas } \\ \text { GDP } & \text { Gross domestic product }\end{array}$

Mvomo Ndzinga Edouard

ndzingaedouard@gmail.com

Pingchuan Dong

dpcfem@163.com

1 College of Petroleum Engineering, China University of Petroleum, Beijing 102249, China

2 State Key Laboratory of Petroleum Resources and Prospecting, China University of Petroleum, Beijing 102249, China

3 School of Geology and Mining Engineering, Meiganga, University of Ngaoundere, Ngaoundere, Cameroon

$\begin{array}{ll}\text { IOR } & \text { Improved oil recovery } \\ \text { IP } & \text { Injection pressure (psi) } \\ \text { ISC } & \text { In situ combustion } \\ \text { MMP } & \text { Minimum miscibility pressure (psi) } \\ \text { P-T } & \text { Pressure-temperature } \\ \text { SG } & \text { Single gas } \\ \text { SGAG } & \text { Simultaneous gas alternating gas. } \\ \text { TAG } & \text { Triple alternating gas }\end{array}$

\section{Introduction}

The ever-increasing world population has resulted in a corresponding rise in global energy consumption (Alina et al. 2019). The International Energy Agency's (IEA 2020) world energy outlook 2020 publication revealed that the global primary energy consumption rose from 7 Gtep in 1977 to 14 Gtep in 2017. Furthermore, fossil fuels largely dominated the global primary energy mix in 2017 (81\%). Petroleum products ( $32 \%$ in 2017), coal, and natural gas (27\%

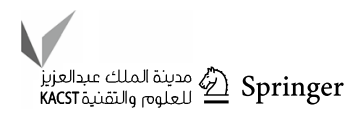


and 22\%) remained, in that order, the top three sources of global energy supply. All this huge amount of energy had impacted negatively on the environment and has resulted in global warming due to $\mathrm{CO}_{2}$ emissions (Sher et al. 1998). The sulfur left in fuels could result in the emission of toxic gases that react with water to form acid rain, thereby leading to environmental, health, and safety hazards (Tawfik 2020; 2021a, b). Notwithstanding, several studies have projected that fossil fuels will remain dominant in the future global energy supply (Alina et al. 2019; Okere et al. 2020; 2021a, b; He et al. 2021). To meet the global demand for fossil fuels (particularly crude oil), efficient enhanced oil recovery (EOR) techniques are necessary (Tawfik and Mukaila 2019; 2021; Okere et al. 2020).

Generally speaking, EOR techniques are classified into thermal and non-thermal processes. These processes modify crude oil properties (such as density and viscosity) to improve oil circulation in the reservoir and eventually improve oil recovery (Handy et al. 2019; Mukaila and Tawfik 2020). The thermal EOR process is classified into steam, combustion, and hot water (Kovscek et al. 2013; Aysylu et al. 2020). Non-thermal EOR includes microbial, chemical, and miscible flooding. Chemical EOR is one of the critical EOR techniques that have been applied in some oil fields (Ali and Hamid 2020). Established chemical EOR techniques include polymer flooding (Ali and Hamid 2020), alkaline flooding (Phukan et al. 2019), surfactant flooding (Druetta and Picchionic 2020), and gas EOR (Mydland et al. 2020). However, there are the two main types of gas injection, namely miscible and immiscible gas injection (Pourhadi et al. 2020). In miscible gas injection, gas is injected at or above the minimum miscibility pressure (MMP) which makes the gas miscible in oil. On the other hand, in the injection of immiscible gas, the flooding with the gas takes place below the MMP (Aref et al. 2014). This low-pressure gas injection maintains the reservoir pressure and increases the production rate (Hoss et al. 2019).

Several research publications have indicated that the existing gas injection methods aforementioned could only provide about $14 \%$ increases from the previous EOR methods (Mohammed et al. 2019; Lino and Akhil 2018; Kamali and Cinar 2014). Researchers and field experts have successfully implemented sequencing gas injection schemes such as double alternating gas (DAG), simultaneous gas alternating gas (SGAG), and water alternating gas (WAG) as a more efficient gas EOR technique (Abdelaziz et al. 2018; Ahmed et al. 2021; Aliya et al. 2016; Roozbeh et al. 2012; Mvomo et al. 2021). However, only a few studies have attempted a triple-gas injection scheme (Bougre and Gamadi 2021). It is important to mention that gas injection EOR becomes more challenging in tight oil reservoirs that are characterized by extremely low permeability, porosity, and complicated reservoir configurations (Zuloaga-Molero et al. 2016; Abdullah and Hasan 2021). For this reason, scholars recently developed optimized gas EOR and sequencing techniques verified via experimental, numerical simulations, and field applications (Yong et al 2016; Vo Thanh et al. 2020; Lino and Akhil 2018). However, the efficiency of an optimal multiple-gas injection scheme (such as the triple-gas injection process) is yet to be explored. Hence, it is necessary to evaluate the efficiency of an optimized multiple-gas injection scheme, to guide during critical decisions regarding the application of gas EOR techniques in the field.

Given the scarcity of research on optimized multiple-gas injection schemes, this study is aimed at proposing an optimized triple-alternating-gas (TAG) injection scheme. The feasibility of the proposed method was verified through comparative simulations that are based on field data. First, the reservoir compositional model is developed to establish the properties and composition of the crude oil. Second, based on the established model, several possible gases were simulated to select a suitable combination for the single gas (SG), DAG, and TAG. Third, the TAG process is optimized and best case parameters are derived. Fourth, comparative simulations for SG, DAG, and TAG were performed using the optimized parameters. Finally, a comparison of the sweep efficiency and mechanisms is explained. It is expected that the research results will provide a practical guide for future field development of tight oil reservoirs.

\section{Methodology}

\section{Development of the compositional reservoir model}

Following the established guidelines of previous publications, a field-scale compositional model is built using CMGWINPROP; the model is specifically developed for the characterization of fluids, PVT data, MMP calculation, and fluid composition (Gbadamosi et al. 2019). The Peng-Robinson equation of state (PR-EOS) is a fundamental model used in oil and gas industries, so we describe the phase behavior of the gas-oil systems using this PR-EOS model as the equation of state. The PR-EOS model (Peng and Robinson 1976) can be expressed as:

$p=\frac{R T}{v b}+\frac{a}{v(v+b)+b(v-b)}$

where

$$
\begin{aligned}
& a=0.457 \frac{R^{2} T_{c}^{2}}{P_{c}^{2}} \\
& b=0.078 \frac{R T_{c}}{P_{c}}
\end{aligned}
$$


At critical points, the conditions of liquids and their vapor state are identical; therefore, Eqs. (2) and (3) become;

$b(T)=b\left(T_{c}\right)$

$a=b \times \beta\left(T_{r}, \omega\right)$

Hence, the Soave-type beta function $(\beta)$ used in the PREOS model is expressed as (Peng and Robinson, 1976):

$\beta\left(T_{r}, \omega\right)=1+\left(0.37464+1.54226 \omega-0.26992 \omega^{2}\right)\left(1-T_{r}^{0.5}\right)$

In these equations, $P$ and $P_{c}$ are gas pressure and critical pressure, respectively, $R$ is gas constant. $T, T_{r}$, and $T_{c}$ are temperature, residual temperature, and critical temperature, respectively, $v$ is specific volume, $\omega$ represents the acentric factor, and $a$ and $b$ are attraction and repulsion parameters, respectively.

\section{Design of the simulation process}

The crude oil utilized in the simulation process comprises twelve components, namely $\mathrm{CO}_{2}, \mathrm{~N}_{2}-\mathrm{CH}_{4}, \mathrm{C}_{2} \mathrm{H}_{6}, \mathrm{C}_{3} \mathrm{H}_{8}$, $\mathrm{IC}_{4}-\mathrm{NC}_{4}, \mathrm{IC}_{5}-\mathrm{NC}_{5}, \mathrm{C}_{6}, \mathrm{C}_{7}-\mathrm{C}_{10}, \mathrm{C}_{11}-\mathrm{C}_{13}, \mathrm{C}_{14}-\mathrm{C}_{17}, \mathrm{C}_{18}-\mathrm{C}_{21}$, and $\mathrm{C}_{22+}$. The corresponding molar fractions are 0.2600052 , 25.056501, 11.868237, 9.7581952, 6.399128, 4.0290806, 3.3790676, 18.346367, 7.8721574, 6.0911218, 3.2440649, and 3.6960739, respectively. (Runxuan et al. 2019; Wei et al. 2015). The properties of the injected fluid were the same as in our previous publication (Mvomo et al. 2021). The model comprises $30 \times 30 \times 5$ grids blocks, with corresponding length, width, and height of $200 \mathrm{ft} \times 400 \mathrm{ft} \times 35 \mathrm{ft}$, respectively. The simulated shale reservoir properties for the base case are shown in Table 1.

The injection cycles and simulation run time were fifteen years. Multiple simulations of the gas injection and sequencing process are carried out to compare several gas-EOR mechanisms. The combination of the simulated injection scheme includes $\mathrm{SG}$ injection $\mathrm{O}_{2}, \mathrm{H}_{2} \mathrm{~S}, \mathrm{CO}_{2}, \mathrm{~N}_{2}$; DAG injection $\left(\mathrm{CO}_{2}+\mathrm{O}_{2}\right),\left(\mathrm{CO}_{2}+\mathrm{CH}_{4}\right),\left(\mathrm{CO}_{2}+\mathrm{H}_{2} \mathrm{~S}\right),\left(\mathrm{CO}_{2}+\mathrm{N}_{2}\right)$; and TAG injection $\left(\mathrm{CO}_{2}+\mathrm{CH}_{4}+\mathrm{H}_{2} \mathrm{~S}\right),\left(\mathrm{CO}_{2}+\mathrm{CH}_{4}+\mathrm{N}_{2}\right)$, $\left(\mathrm{CO}_{2}+\mathrm{CH}_{4}+\mathrm{O}_{2}\right),\left(\mathrm{CO}_{2}+\mathrm{H}_{2} \mathrm{~S}+\mathrm{O}_{2}\right),\left(\mathrm{CO}_{2}+\mathrm{N}_{2}+\mathrm{O}_{2}\right)$.

\section{Results and discussion}

\section{Results of the reservoir compositional model}

The results of the properties and composition of the tight oil are shown in Table 2.

The simulation prediction of the pressure-temperature (P-T) two-phase boundary for the reservoir fluid composition is presented in Fig. 1.
Table 1 Simulation details of the base case model of reservoir properties (Mvomo et al. 2021; Ehsan et al. 2018; Chen et al. 2018)

\begin{tabular}{ll}
\hline Variable name & Value \\
\hline Grids & $30 \times 30 \times 5$ \\
Reservoir depth (ft) & $8500-9000$ \\
Thickness (ft) & $35-50$ \\
Porosity (\%) & 9 \\
Permeability (I) (layer1 ...layer5) (mD) & $0.0272-0.1445$ \\
Permeability (J) (layer1...layer5) (mD) & $0.0272-0.1445$ \\
Permeability (K) (layer1...layer5) (mD) & $0.0272-0.1445$ \\
Oil density (lb/ft ${ }^{3}$ ) & $49-60$ \\
Oil viscosity (cp) & $0.3-45$ \\
GOR (scf/bbl) & $28-2000$ \\
Water saturation & 0.4 \\
Initial oil saturation & 0.6 \\
Injection pressure (psi) & 8700 \\
Bubble-point pressure (psi) & 2500 \\
MMP (psi) & 3600 \\
Reservoir gas injection rate (ft ${ }^{3} /$ day) & 20,000 \\
Surface liquid rate (bbl/day) & 300 \\
\hline
\end{tabular}

Table 2 Properties and composition of tight oil sample

\begin{tabular}{lllll}
\hline Components & Pc (atm) & Tc (K) & $\begin{array}{l}\text { Acentric } \\
\text { factor }(\omega)\end{array}$ & $\begin{array}{l}\text { Molecular } \\
\text { weight }\end{array}$ \\
\hline $\mathrm{CO}_{2}$ & 72.8 & 304.2 & 0.225 & 44.01 \\
$\mathrm{~N}_{2}-\mathrm{CH}_{4}$ & 44.89 & 187.59 & 0.0094 & 16.58 \\
$\mathrm{C}_{2} \mathrm{H}_{6}$ & 48.2 & 305.4 & 0.098 & 30.07 \\
$\mathrm{C}_{3} \mathrm{H}_{8}$ & 41.9 & 369.8 & 0.152 & 44.1 \\
$\mathrm{IC}_{4}-\mathrm{NC}_{4}$ & 37.17 & 421.49 & 0.1894 & 58.12 \\
$\mathrm{IC}_{5}-\mathrm{NC}_{5}$ & 33.34 & 466.18 & 0.2421 & 72.15 \\
$\mathrm{C}_{6}$ & 32.46 & 507.5 & 0.275 & 86 \\
$\mathrm{C}_{7}-\mathrm{C}_{10}$ & 25.15 & 627.21 & 0.3205 & 137.76 \\
$\mathrm{C}_{11}-\mathrm{C}_{13}$ & 20.22 & 684.14 & 0.4595 & 198.2 \\
$\mathrm{C}_{14}-\mathrm{C}_{17}$ & 17.15 & 733.42 & 0.5751 & 255.58 \\
$\mathrm{C}_{18}-\mathrm{C}_{21}$ & 15.74 & 791.36 & 0.7013 & 322.9 \\
$\mathrm{C}_{22+}$ & 10.57 & 1066.91 & 1.1184 & 344.97 \\
\hline
\end{tabular}

The $\mathrm{P}-\mathrm{T}$ phase envelopes of tight oil are investigated as illustrated in Fig. 1; indeed, the noticeable difference caused by the capillarity effect on bubble-point pressures achieved as high as 1000 psi. Indeed, for tight oil reservoirs, the mixture remains in the single-phase region where the pressure is higher than the bubble-point pressure. Moreover, the drop in the bubble-point pressure is the single-phase region which leads to suppression and has a positive influence on the performance of vertical wells in tight oil reservoirs. The cumulative oil production can be improved as high as 7\% (Subero 2009; Yuan et al. 2017). 


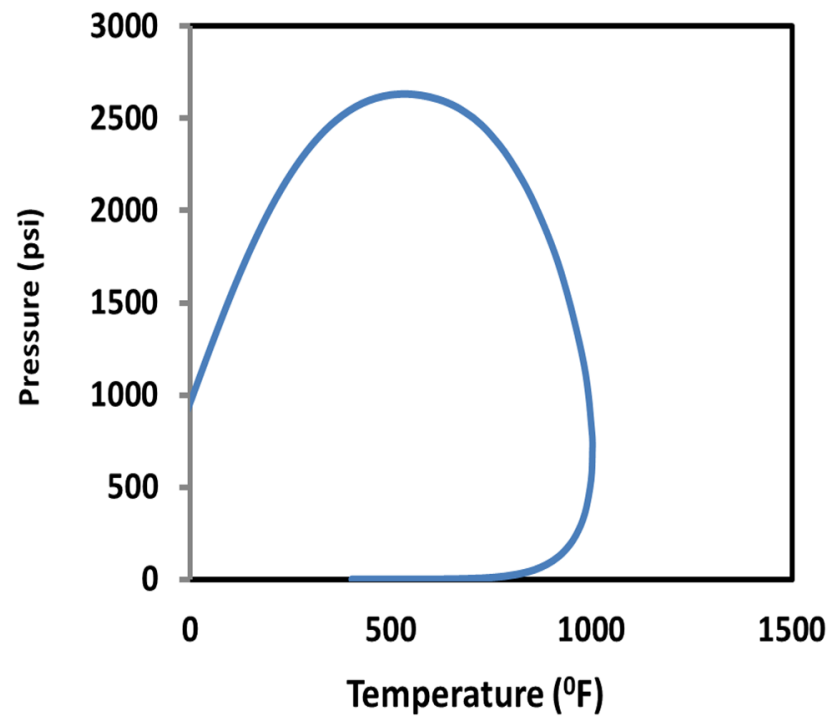

Fig. 1 WinProp two-phase flash results showing the predicted twophase boundary

\section{Results of the comparative simulation for the design of TAG injection}

Based on the simulation design in Sect. Design of the simulation process, the results of the comparative numerical simulation for base case SG, DAG, and TAG injection process are shown in Fig. 2.

As Fig. 2a shows, $\mathrm{N}_{2}$ has the highest oil recovery factor at approximately $47.2 \%$. This is because, when $\mathrm{N}_{2}$ is injected into the reservoir, the gravity difference between oil and other formation fluids increases the oil recovery and formation pressure, thereby supplying sufficient formation energy that will improve the oil displacement efficiency (Xinrui et al. 2017). Although the recovery factor of $\mathrm{N}_{2}$ injection is high under miscible conditions favoring the vaporization of light fractions of light oils and condensates, only a few $\mathrm{N}_{2}$ floods have been reported in recent times; hence, we do not foresee an increment in the number of projects implementing this EOR gas flooding method. $\mathrm{CO}_{2}$ provided nearly the same oil recovery factor at $\mathrm{N}_{2}$ at approximately $45 \%$. The injected $\mathrm{CO}_{2}$ mixes with the reservoir oil either at first contact or after several contacts, thus improving the volumetric sweeping and displacement efficiencies (Abdelaziz et al. 2018). $\mathrm{CO}_{2}$ flooding has been the most widely used singlegas method for medium and light oil production. The recovery factor of other gasses such as $\mathrm{H}_{2} \mathrm{~S}$ and $\mathrm{O}_{2}$ was relatively lower at about $36 \%$ and $6 \%$, respectively.

Figure $2 \mathrm{~b}$ indicates that the injection of $\mathrm{CO}_{2}+\mathrm{CH}_{4}$ provides a high recovery factor of about $55.3 \%$, while the recovery factor of $\mathrm{CO}_{2}+\mathrm{N}_{2}$ is close at approximately $54.3 \%$. However, the recovery factors of $\mathrm{CO}_{2}+\mathrm{H}_{2} \mathrm{~S}$ and $\mathrm{CO}_{2}+\mathrm{O}_{2}$ were significantly low at $44.6 \%$ and $8.2 \%$, respectively. This
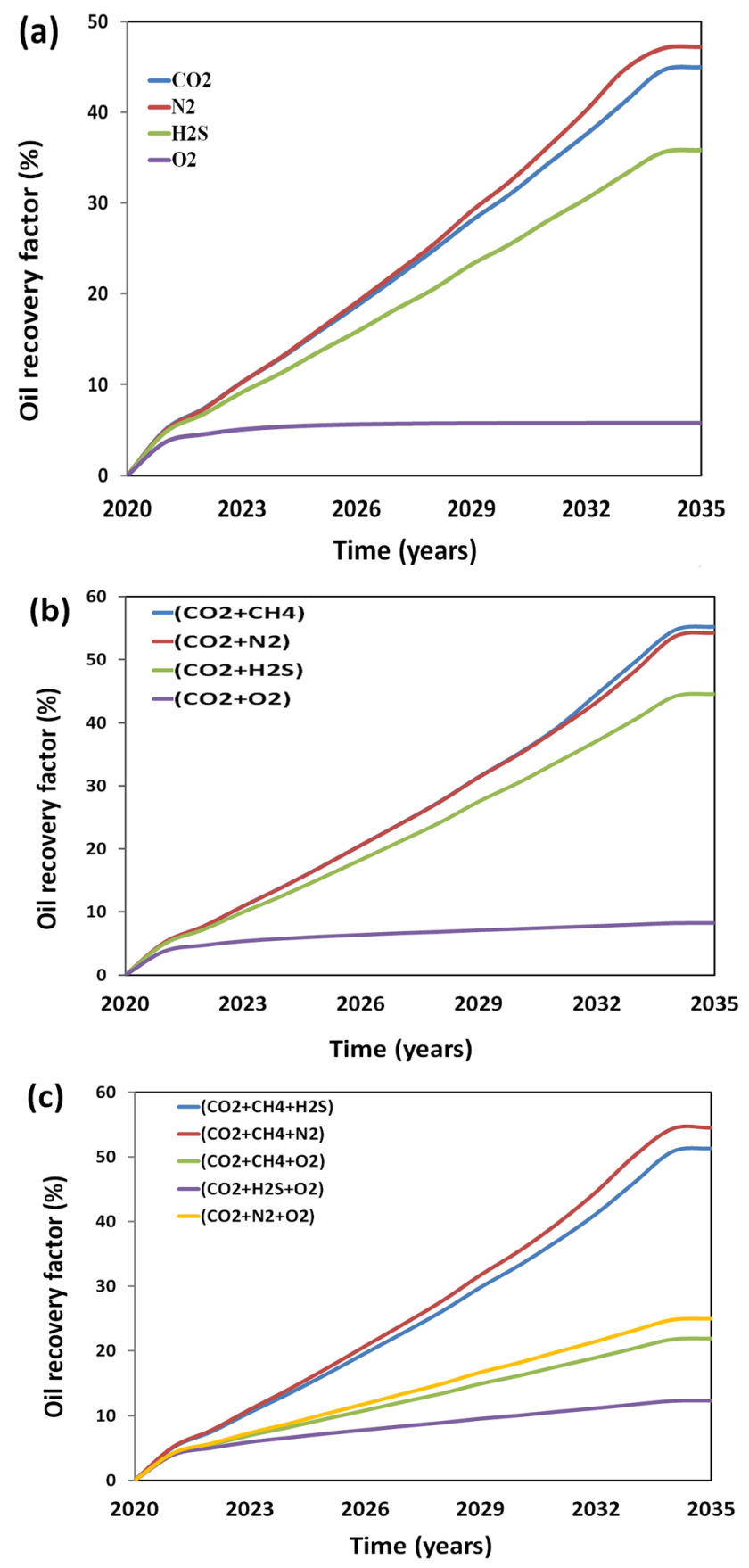

Fig. 2 Comparative simulation results for a SG; b DAG; c TAG

result conforms to the outcome of existing literature. Herein, the microscopic displacement efficiency is improved by reducing or removing the interfacial tension between the oil and the miscible gas (Muggeridge et al. 2014).

As Fig. 2c indicates, the recovery factors, arranged from highest to lowest, are as follows: $\mathrm{CO}_{2}+\mathrm{CH}_{4}+\mathrm{N}_{2}$ $(54.5 \%)>\mathrm{CO}_{2}+\mathrm{CH}_{4}+\mathrm{H}_{2} \mathrm{~S}(51.3 \%)>\mathrm{CO}_{2}+\mathrm{N}_{2}+\mathrm{O}_{2}$ $(25 \%)>\mathrm{CO}_{2}+\mathrm{CH}_{4}+\mathrm{O}_{2}(21.9 \%)>\mathrm{CO}_{2}+\mathrm{H}_{2} \mathrm{~S}+\mathrm{O}_{2}(12 \%)$. During the injection, the residual oil saturation is reduced by 
creating a miscible contact (Muggeridge et al. 2014; Zendehboudi et al. 2013; Farajzadeh et al. 2012; Teletzke et al. 2005; Gbadamosi et al. 2018).

In summary, for the base case simulation results, DAG and TAG provided a higher recovery factor than the SG injection method. Based on the high recovery factor, economic advantages, and availability of the gases, we, respectively, select $\mathrm{CO}_{2},\left(\mathrm{CO}_{2}+\mathrm{H}_{2} \mathrm{~S}\right)$, and $\left(\mathrm{CO}_{2}+\mathrm{CH}_{4}+\mathrm{H}_{2} \mathrm{~S}\right)$ for $\mathrm{SG}, \mathrm{DAG}$, and TAG analysis in subsequent sections. Furthermore, to optimize the selected TAG injection scheme, a sensitivity analysis is conducted in subsequent sections.

\section{Results of sensitivity analysis on the TAG injection scheme}

Herein, the performance of the selected TAG injection scheme is optimized using four parameters, namely cycle time, volume ratio, injection pressure, and production pressure at selected scenarios. Detailed description of these sensitivity analyses is shown in the following sections.

\section{Optimization of cycle time}

The TAG cycle time defines as the alternation of the injection of three gases with equal or different durations between them. The selected simulation cycle times are 0.5 years; 1 year (i.e., base case); 2 years; and 3 years. The simulation result is shown in Fig. 3.

As Fig. 3 indicates, the 0.5-year cycle gives the highest recovery factor. This is because it is more favorable to inject $\mathrm{CO}_{2}, \mathrm{CH}_{4}$ and $\mathrm{H}_{2} \mathrm{~S}$ at the shortest possible time to attain the gas-oil miscibility at the pressure above minimum miscibility pressure. Further, for all cases, the oil production significantly increased with time. Therefore, the optimal cycle time is 6 months.

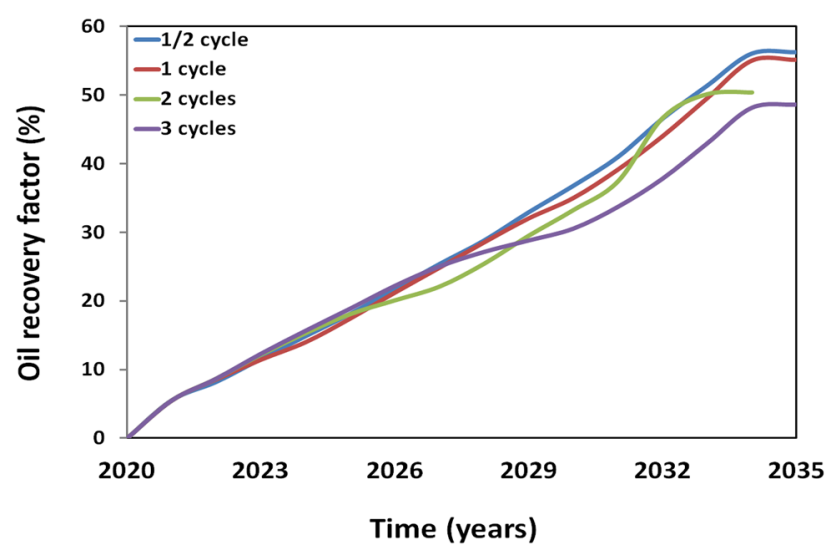

Fig. 3 Simulation results of selected cycle time

\section{Optimization of injection volume ratio}

The injection volume ratio defines as the ratio of the volume of gas injected per day. The simulated volume ratios used for optimizing the TAG injection are presented in Table 3.

To analyze the effect of the quantity of gas injected on the oil recovery, the volumetric ratios established in Table 3 were simulated against the oil recovery factor as shown in Fig. 4.

As Fig. 4 shows, for all injected volume ratios, the oil recovery factor constantly increased (one of the advantages of the miscible TAG injection scheme). Furthermore, the ratio $3: 1$ provided the most efficient oil recovery, which can be attributed to the theory that explains that gases have relatively high mobility compared to oil; thus, breakthrough of gases will easily occur. In this regard, increasing the volume ratio enhances the volumetric sweep efficiency, thereby improving the performance of the TAG process.

Table 3 Selected injection volume ratios for optimizing the TAG process

\begin{tabular}{lllll}
\hline S/N & TAG ratio & $\begin{array}{l}\text { Gas rate } \mathrm{CO}_{2} \\
\left(\mathrm{ft}^{3} / \text { day }\right)\end{array}$ & $\begin{array}{l}\mathrm{Gas} \text { rate } \mathrm{CH}_{4} \\
\left(\mathrm{ft}^{3} / \text { day }\right)\end{array}$ & $\begin{array}{l}\mathrm{Gas} \text { rate } \\
\mathrm{H}_{2} \mathrm{~S}\left(\mathrm{ft}^{3} /\right. \\
\text { day })\end{array}$ \\
\hline 1 & $1: 1 / 2$ & 20,000 & 10,000 & 10,000 \\
2 & $1: 1$ (base case) & 20,000 & 20,000 & 20,000 \\
3 & $1: 2$ & 20,000 & 40,000 & 40,000 \\
4 & $1: 3$ & 20,000 & 60,000 & 60,000 \\
5 & $2: 1$ & 40,000 & 20,000 & 20,000 \\
6 & $3: 1$ & 60,000 & 20,000 & 20,000 \\
\hline
\end{tabular}

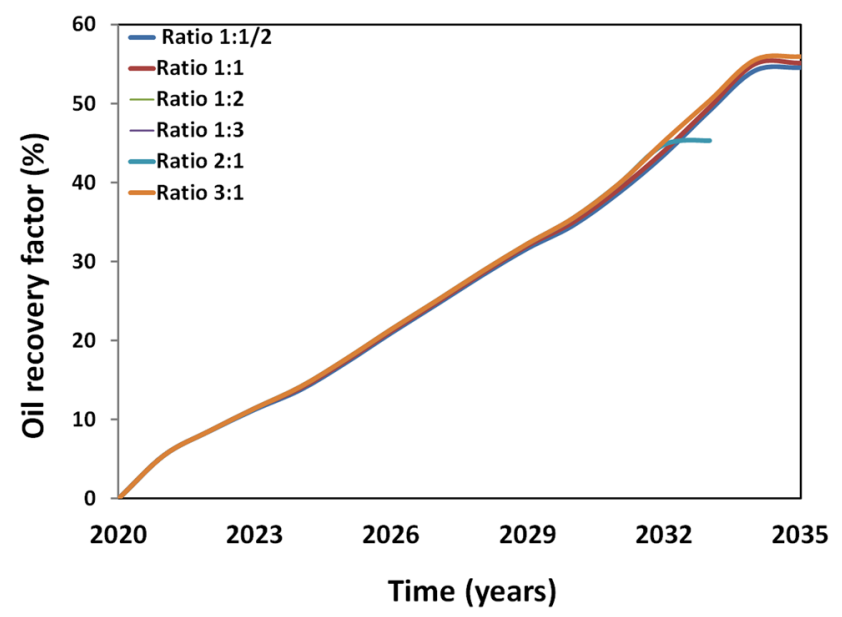

Fig. 4 Simulation results of selected injection volume ratio

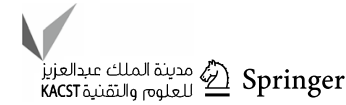




\section{Optimization of injection pressure}

The minimum miscibility pressure (MMP) is a key criterion when designing for injection pressure (IP) during gas EOR (Mohamed et al. 2021). When the IP is below the MMP, there is no significant oil recovery; however, when the IP is higher than the MMP, there will be a significant increase in oil recovery. Additionally, studies have shown that for miscible gasses such as $\mathrm{CO}_{2}$ and $\mathrm{CH}_{4}$, the oil recovery factor increases (Abdelaziz et al. 2018). Herein, the selected IP is greater than or equal to the MMP (i.e., IP $\geq$ MMP). The selected IP is 2000 psi; 4000 psi; 6000 psi; and 8000 psi (i.e., base case). The simulation result is shown in Fig. 5.

As Fig. 5 indicates, the optimal IP is 8000 psi. In addition, the simulation result also illustrates that more oil is produced when the injection pressure increases from 2000 to 8000 psi. Below 6000 psi, the injection pressure had less effect on oil recovery; hence, additional pressure increases gas sweep volume and allows the oil and gas to attain a miscible condition.

\section{Optimization of production pressure}

The production pressure is maintained above the MMP because the gases will mix with the hydrocarbons and flow together in one phase. The first contact MMP is approximately $5500 \mathrm{psi}$, while the multi-contact miscibility is approximately 2200 psi. Hence, the selected production pressure is $1000 \mathrm{psi}$; $2000 \mathrm{psi} ; 3000 \mathrm{psi}$ (base case), and 4000 psi. The simulation result is shown in Fig. 6.

Figure 6 shows that 1000 psi is optimal production pressure. This indicates that the lower the production pressure, the lesser the tendency to attain miscibility (Savjani et al. 2012). Additionally, the oil recovery rate is inversely proportional to the production pressure.

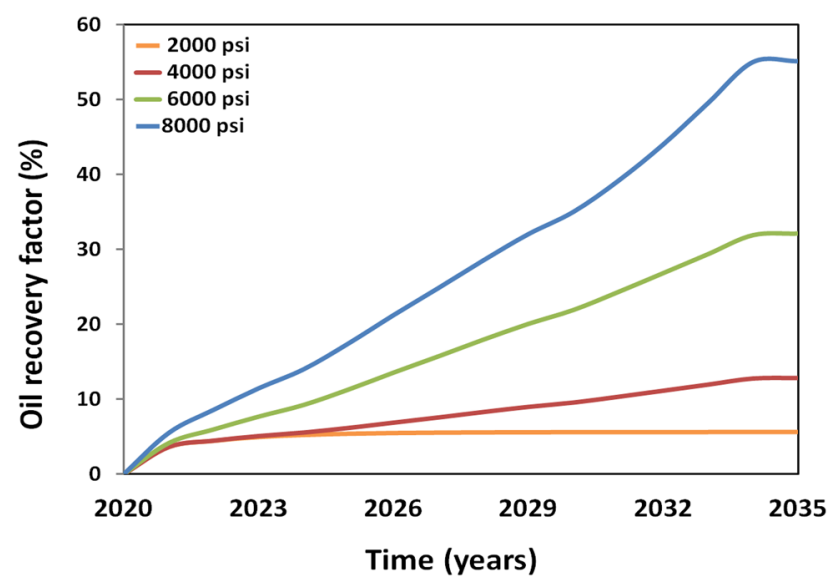

Fig. 5 Simulation results of selected IP

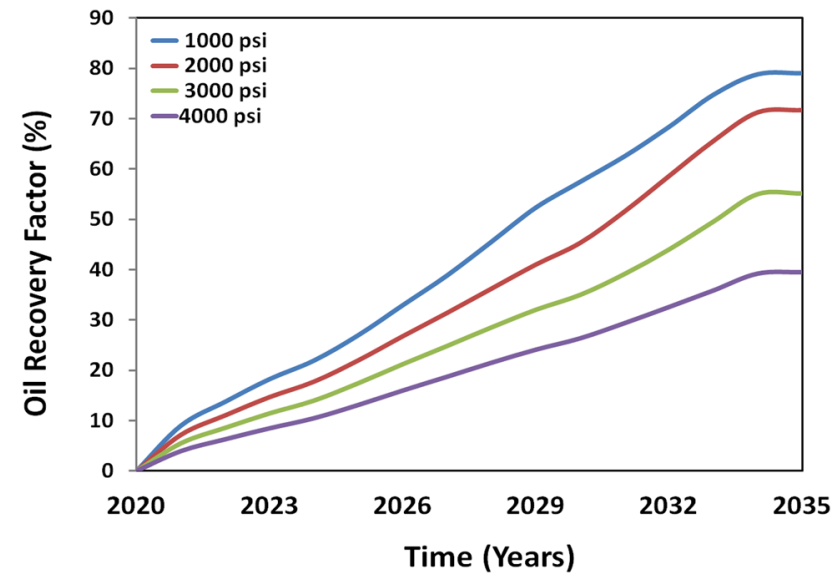

Fig. 6 Sensitivity analysis optimization of TAG production pressure

The sensitivity analysis has shown that the performance of the TAG injection scheme is more sensitive to the injection and the production pressures. To evaluate the efficiency of the TAG method, the optimized parameters are used to perform comparative simulations for TAG, DAG, and SG injections.

\section{Results of comparative simulation of TAG, DAG, and SG injections}

In this section, the performances of the selected combination of gasses (in Sect. Results of the comparative simulation for the design of TAG injection) were compared before and after optimization. It is important to note that the comparative simulation before optimization was carried using the base case parameters, while the best case (optimized) parameters were used for simulating after optimization. The results of the comparative simulation before and after optimization for SG, DAG, and TAG injections are highlighted in Fig. 7.

Figure 7 shows that before optimization, the recovery factor for TAG, DAG, and SG was 55.14\%, 51.32\%, and $44.96 \%$, respectively. However, after optimization, the recovery factor for TAG, DAG, and SG was $84.74 \%$, $78.61 \%$, and $63.14 \%$, respectively. This implies that the TAG injection EOR process increased the percentage oil recovery factor of the DAG and SG by approximately $8 \%$ and $34 \%$, respectively. Thus, the above analysis confirmed the effectiveness of the TAG injection scheme in enhancing oil recovery from tight oil reservoirs; however, a comparison of the volumetric sweep efficiency will further validate the findings of this study.

\section{Results of comparative simulation of the volumetric sweep efficiency during SG, DAG, and TAG injections}

Herein, the volumetric sweep efficiency of the selected combination of gasses (in Sect. 4.2) was compared before and 


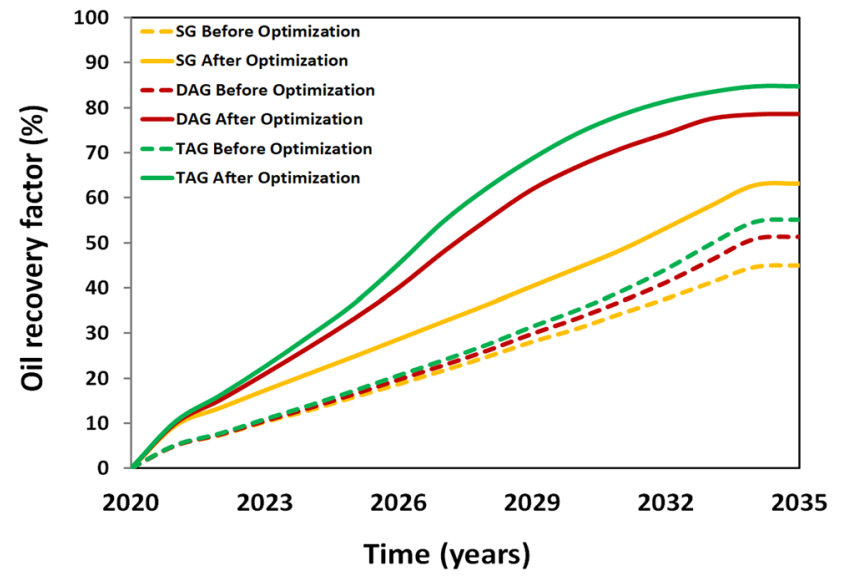

Fig. 7 Results of the comparative simulation before and after optimization for SG, DAG, and TAG injection after optimization. The simulation was performed at intervals of five years, starting from 2020 to 2035. The results of the comparative simulation before and after optimization for SG, DAG, and TAG injections are highlighted in Fig. 8.

It can be seen in Fig. 8 that after optimization, the sweep efficiency greatly improved better than that before. This occurs when the gas breakthrough increases with a corresponding increase in gas injection rates. Interestingly, the volumetric sweep efficiency of the TAG injection scheme was the best. The mixture of gas and crude oil will result in a volumetric expansion of the crude oil, the microscopic displacement efficiency, and the vertical sweep efficiency due to gravity override (Fig. 9).

Scholars have demonstrated that the primary mechanism for oil recovery in a gas injection process is the change in mass between the oil and gas phases (Gbadamosi et al. 2019). The mass transfer increases and forms a miscible plug in front of the gas phase (Biswerwar et al. 2020; Sikandar et al. 2020). Higher efficiency of miscible gas flooding is attributed to a high mass transfer between the oil and gas phases (Fig. 9), which results in reduced viscosity of the

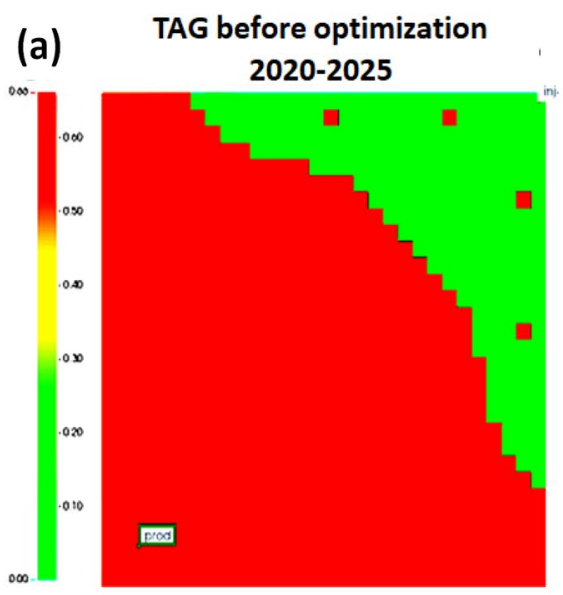

TAG after optimization 2020-2025

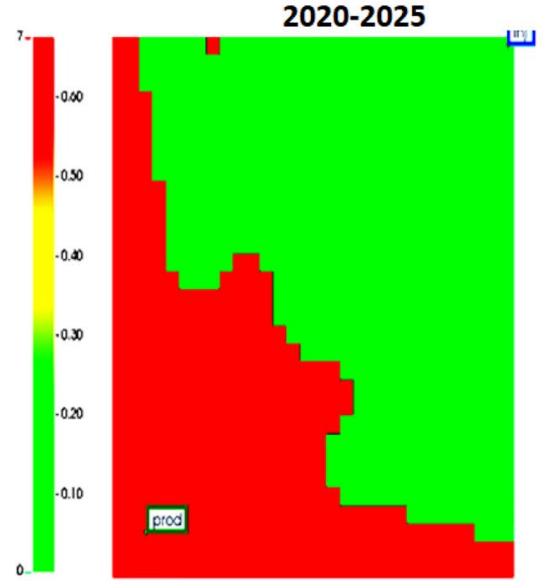

TAG before optimization

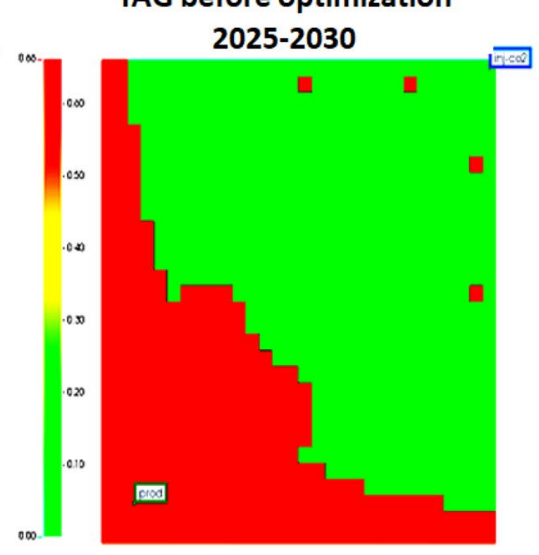

TAG after optimization 2025-2030

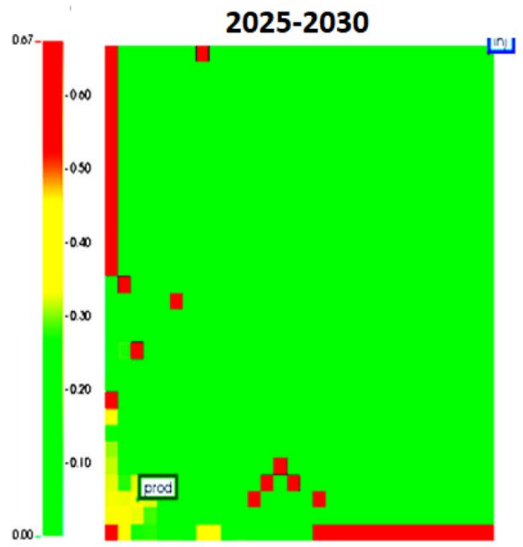

TAG betore optimization 2030-2035

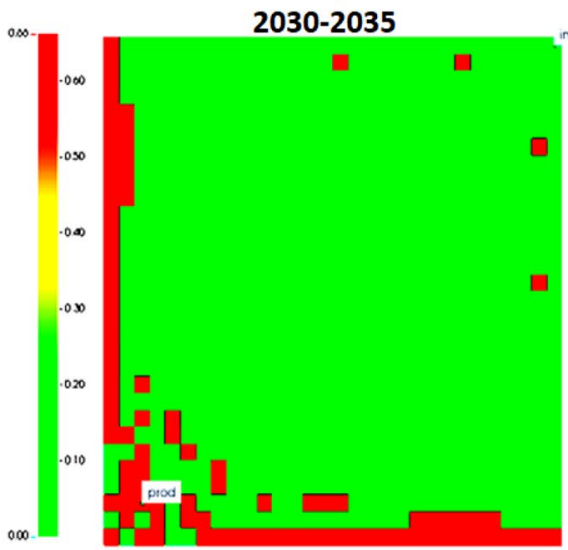

TAG after optimization 2030-2035

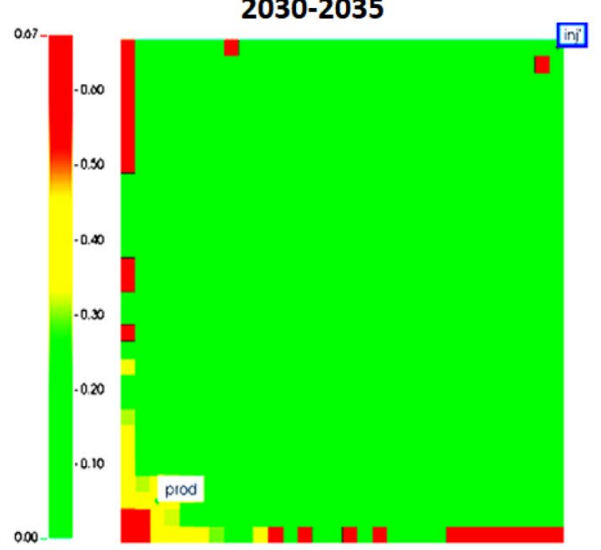

Fig. 8 Results of comparative simulation of the volumetric sweep efficiency: a TAG; b DAG; $\mathbf{c}$ SG 

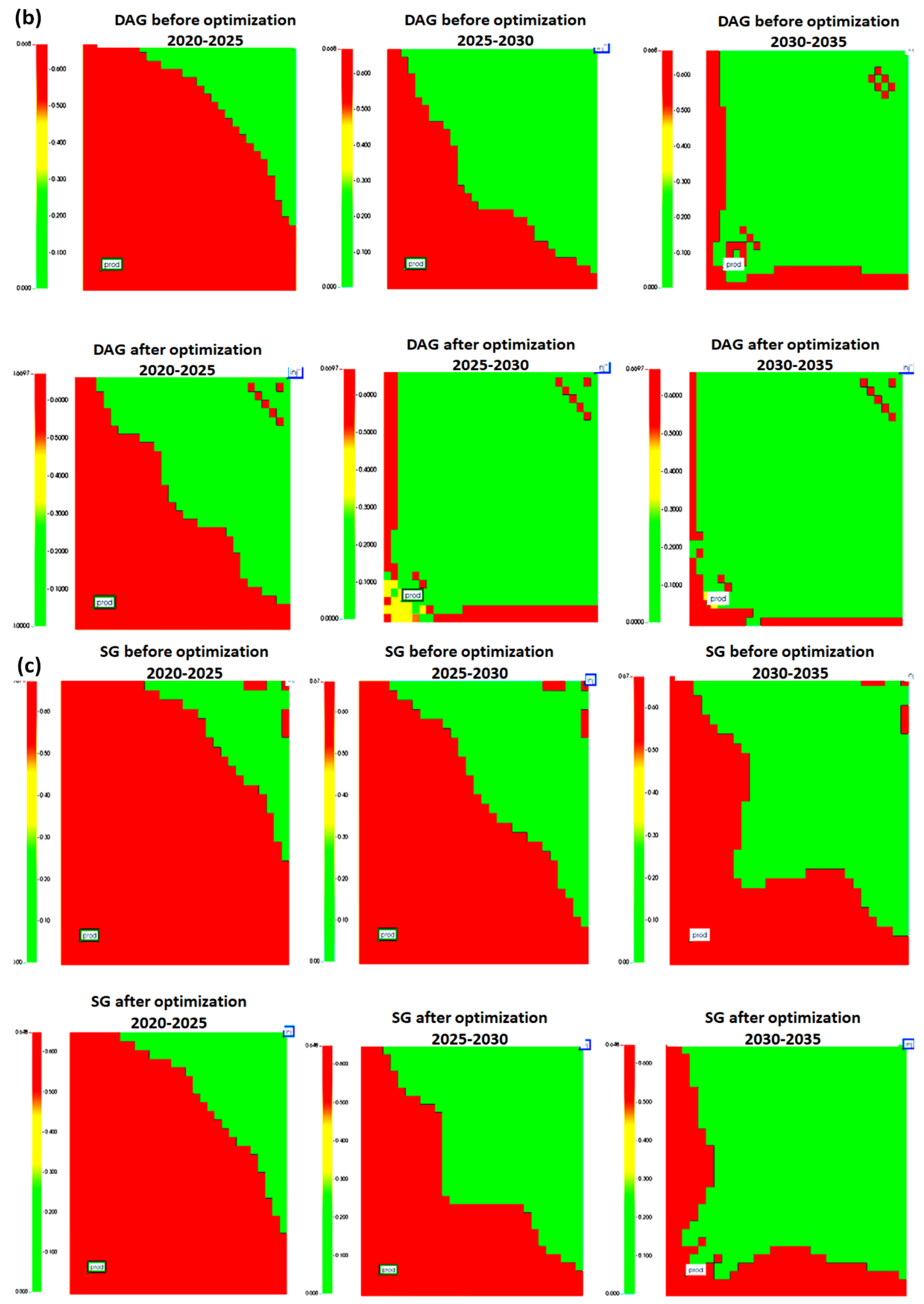

Fig. 8 (continued) 
Fig. 9 Schematic process of the mechanism of TAG injection

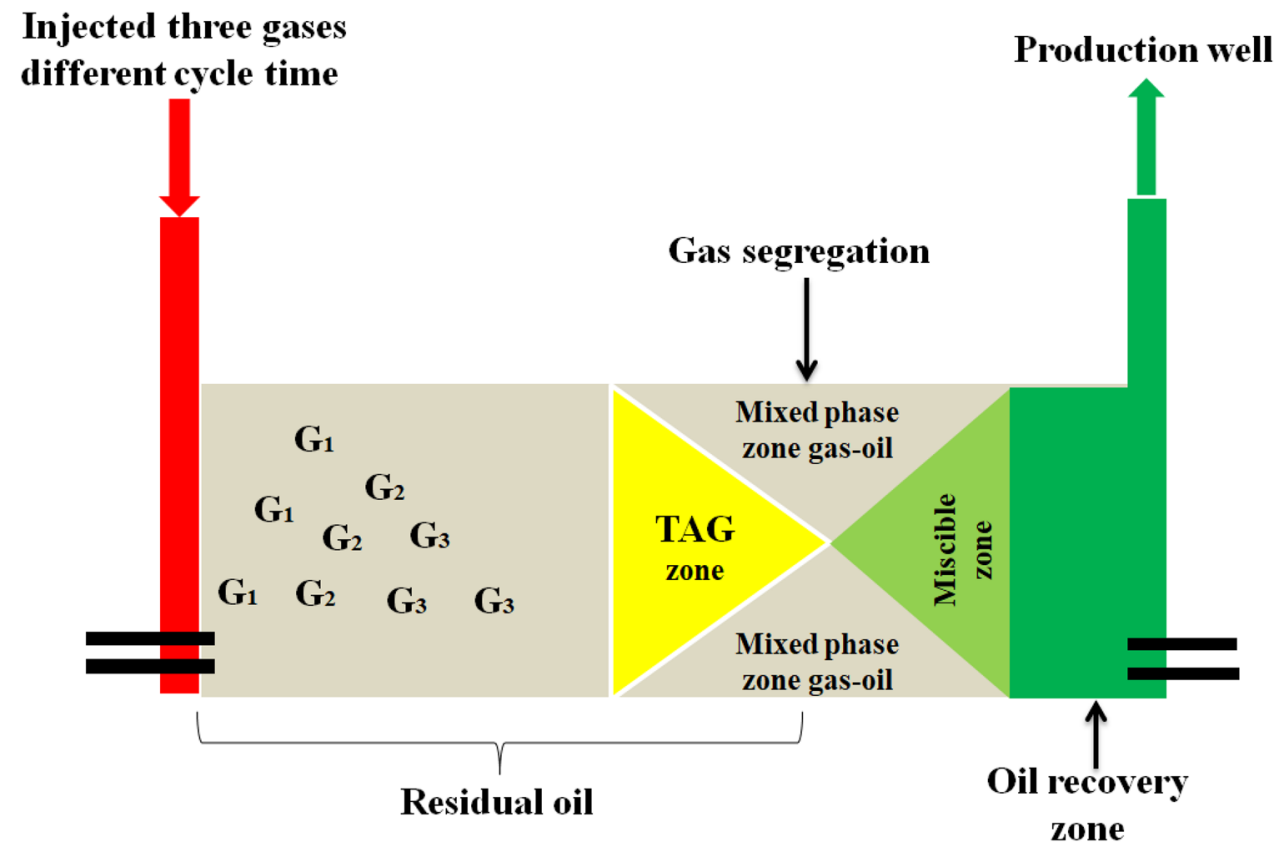

oil and swelling of the oil; thus, greater viscous forces are obtained, leading to better macroscopic and microscopic efficiencies (Sohrabi et al. 2008; Gbadamosi et al. 2019). In addition, the swelling and the decrease in the viscosity of the oil phase are activated during the flooding of the gas due to the condensation of the intermediate components of the gas in the oil phase (Johannes2015). The gas always extracts some components from the oil phase (Boyun et al. 2007). Therefore, the efficiency of oil transport by gas can be explained by the concept of MMP (Wang et al. 2020). When the gas injection is maintained above the MMP, a high oil recovery factor is achieved (Bisweswar et al. 2020). However, the MMP is not the same for different gases, and it is generally much higher for $\mathrm{N}_{2}$ than for $\mathrm{CO}_{2}$; therefore, for an $\mathrm{N}_{2}$ oil system, the miscibility condition is more difficult to achieve (Bougre et al. 2021). Usually, the injection of $\mathrm{CO}_{2}$ is more efficient than the injection of other non-hydrocarbon gases (Hadi et al. 2013).

\section{Conclusions and recommendation}

An optimal TAG tertiary recovery operation was proposed for improved oil recovery in unconventional oil resources. This study provides a reliable basis for the optimization of multiple injection miscible gas techniques. The following points have been covered:

1. Based on the high recovery factor, economic advantages and availability of the gases, $\mathrm{CO}_{2},\left(\mathrm{CO}_{2}+\mathrm{H}_{2} \mathrm{~S}\right)$, and $\left(\mathrm{CO}_{2}+\mathrm{CH}_{4}+\mathrm{H}_{2} \mathrm{~S}\right)$ were selected for further design of an optimal SG, DAG, and TAG miscible gas EOR.
2. According to the sensitivity analysis on the selected TAG injection scheme, the optimal cycle time, volume ratio, injection pressure, and production pressure are 6 months, 3:1, 8000 psi, and 1000 psi, respectively. Furthermore, the sensitivity analysis has shown that the performance of the TAG injection scheme is more sensitive to the injection and the production pressures.

3. Comparative simulations of optimal SG, DAG, and TAG showed that that the TAG injection EOR process increased the percentage oil recovery factor of the DAG and SG by approximately $8 \%$ and $34 \%$, respectively. Additionally, the overall sweep efficiency greatly improved.

4. Analysis of the mechanisms revealed that higher efficiency of EOR miscible gas flooding is attributed to a high mass transfer between the oil and gas phases, which results in reduced viscosity and swelling of the oil.

Therefore, the following recommendations are made for future studies: (a) Critical analysis of field applications based on the optimal TAG injection process is necessary to validate the simulation results; (b) a more detailed economic analysis on the TAG process is important; (c) an extensive study on the chemical interaction between the components will further explain the scientific aspect of the mechanisms.

Funding The authors would like to acknowledge the financial support of the China Scholarship Council (Grant No.2019DFJ000912). 


\section{Declarations}

Conflict of interest The authors declare that they have no known competing financial interests or personal relationships that could have appeared to influence the work reported in this paper.

Open Access This article is licensed under a Creative Commons Attribution 4.0 International License, which permits use, sharing, adaptation, distribution and reproduction in any medium or format, as long as you give appropriate credit to the original author(s) and the source, provide a link to the Creative Commons licence, and indicate if changes were made. The images or other third party material in this article are included in the article's Creative Commons licence, unless indicated otherwise in a credit line to the material. If material is not included in the article's Creative Commons licence and your intended use is not permitted by statutory regulation or exceeds the permitted use, you will need to obtain permission directly from the copyright holder. To view a copy of this licence, visit http://creativecommons.org/licenses/by/4.0/.

\section{References}

Abdelaziz NE, Saad D (2018) CO2 miscible flooding for enhanced oil recovery. Geophys Ocean Waves Stud. https://doi.org/10.5772/ intechopen.79082

Abdullah N, Hasan N (2021) Effects of miscible CO2 injection on production recovery. J Petrol Explor Prod Technol 11:3543-3557. https://doi.org/10.1007/s13202-021-01223-0

Ahmed R, Eman MM (2021) Enhanced oil recovery: chemical flooding. Geophys Ocean Waves Stud. https://doi.org/10.5772/intec hopen. 90335

Ali MF, Hamid RS (2020) Review on chemical enhanced oil recovery using polymer flooding: fundamentals, experimental and numerical simulation. Petroleum 6(2):115-122. https://doi.org/10.1016/j. petlm.2019.09.003

Alina Z, Diaconeasa MC, Laura B, Georgiana RL, Corina I (2019) Factors influencing energy consumption in the context of sustainable development. Sustainability. https://doi.org/10.3390/su10072465

Aliya Y, Gulzhan K, Almagul B, Azhar Z (2016) Microbial enhanced oil recovery. Geophys Ocean Waves Stud. https://doi.org/10.5772/ 64805

Aref HF, Abdol RP (2014) Evaluation of miscible and immiscible CO2 injection in one of the Iranian oil fields. Egypt J Pet 23(3):255270. https://doi.org/10.1016/j.ejpe.2014.08.002

Aysylu A, Aman T, Strahinja M, Evgeny P, Kirill M, Gennady U, Valery K, Alexey C (2020) Thermal enhanced oil recovery in deep heavy oil carbonates: experimental and numerical study on a hot water injection performance. J Pet Sci Eng 194:107456. https://doi.org/10.1016/j.petrol.2020.107456

Bisweswar G, Al-Hamairi A, Jin S (2020) Carbonated water injection: an efficient EOR approach. A review of fundamentals and prospects. J Petrol Explor Prod Technol 10:673-685. https://doi.org/ 10.1007/s13202-019-0738-2

Bougre ES, Gamadi TD (2021) Enhanced oil recovery application in low permeability formations by the injections of $\mathrm{CO} 2, \mathrm{~N} 2$ and CO2/N2 mixture gases. J Petrol Explor Prod Technol 11:19631971. https://doi.org/10.1007/s13202-021-01113-5

Boyun G, Ali G (2007) Gravity Segregation. In: Petroleum Production Engineering. Gulf Professional Publishing, 1st edition. Louisiana at Lafayette, pp 3-17

Chen B, Reynolds AC (2018) CO2 water-alternating-gas injection for enhanced oil recovery: Optimal well controls and half-cycle lengths, Computers \& Chemical Engineering, Vol. 113, pp 44-56, https://doi.org/10.1016/j.compchemeng.2018.03.006.
Druetta P, Picchioni F (2020) Surfactant flooding: the influence of the physical properties on the recovery efficiency. Petroleum 6(2):149-162. https://doi.org/10.1016/j.petlm.2019.07.001

Ehsan M, Fatemeh SZ (2018) Fundamentals of Enhanced Oil and Gas Recovery from Conventional and Unconventional Reservoirs. Australia oil and gas services, pty. Ltd, Lismore, NSW, Australia, pp 41-61

Farajzadeh R, Andrianov A, Krastev R, Hirasaki GJ, Rossen WR (2012) Foam-oil interaction in porous media: implications for foam assisted enhanced oil recovery. Adv Colloid Interface Sci 183-184:1-13. https://doi.org/10.1016/j.cis.2012.07.002

Gbadamosi AO, Junin R, Manan MA, Augustine A, Adeyinka SY (2019) An overview of chemical enhanced oil recovery: recent advances and prospects. Int Nano Lett 9:171-202. https://doi.org/ 10.1007/s40089-019-0272-8

Gbadamosi AO, Kiwalabye J, Junin R, Agi A (2018) A review of gas enhanced oil recovery schemes used in the North Sea. J Petrol Explor Prod Technol 8:1373-1387. https://doi.org/10.1007/ s13202-018-0451-6

Hadi B, Hadil A, Khalid J (2013) Miscible oil recovery utilizing N2 and/or HC gases in CO2 injection. J Pet Sci Eng 111:144-152. https://doi.org/10.1016/j.petrol.2013.08.030

Handy M, Abubakar Z, Shakel MR, Habib MA, Mahmoud M (2019) A comprehensive review of thermal enhanced oil recovery: techniques evaluation. J Energy Resour Technol, Trans ASME. https:// doi.org/10.1115/1.4041096

He J, Okere CJ, Su G, Hu P, Zhang L, Xiong WLZ (2021) Formation damage mitigation mechanism for coalbed methane wells via refracturing with fuzzy-ball fluid as temporary blocking agents. J Natural Gas Sci Eng 90:103956. https://doi.org/10.1016/j.jngse. 2021.103956

Hoss B, Fatemeh B (2019) Numerical simulation of real field Marcellus shale reservoir development and stimulation. Hydraul Fract Unconv Reserv (second Edition). https://doi.org/10.1016/ C2018-0-01643-6

IEA 2020. World energy Outlook 2020, IEA, Paris. https://www.iea. org/reports/world-energy-outlook-2020

Johannes F (2015) Enhanced oil recovery. Petroleum engineer's guide to oil field chemicals and fluids (Second Edition), Gulf Professional Publishing. https://doi.org/10.1016/B978-0-12-803734-8. 00016-3

Kamali F Cinar Y (2014) Co-optimizing enhanced oil recovery and $\mathrm{CO} 2$ storage by simultaneous water and $\mathrm{CO} 2$ injection. Energy Exploration \& Exploitation, 32(2), 281-300. http://www.jstor.org/ stable/90006570

Kovscek ARR, Castanier LMM, Gerritsen MGG (2013) Improved predictability of in-situ-combustion enhanced oil recovery. SPE Res Eval Eng 16:172-182. https://doi.org/10.2118/165577-PA

Lino A, Akhil DG (2018) Optimizing CO2 and field gas injection EOR in unconventional reservoirs using the fast marching method. In: Paper presented at the SPE improved oil recovery conference, Tulsa, Oklahoma, USA. https://doi.org/10.2118/190304-MS

Mohammed AS, Ibrahim A, Mahmoud OE (2019) A new EOR technology: gas alternating gas injection. J Earth Energy Eng 8:27-32. https://doi.org/10.25299/jeee.2019.vol8(1).2354

Mohamed A, Zangyuan W, Daiyu Z, Kun F, Yongbing L, Quan X (2021) A review of chemical-assisted minimum miscibility pressure reduction in $\mathrm{CO} 2$ injection for enhanced oil recovery. Petroleum. https://doi.org/10.1016/j.petlm.2021.01.001

Muggeridge A, Cockin A, Webb K, Frampton H, Collins I, Moulds T, Salino P (2014) Recovery rates, enhanced oil recovery and technological limits. Phil Trans R Soc A. https://doi.org/10.1098/ rsta.2012.0320

Mukaila AI, Tawfik AS (2020) Partially aminated acrylic acid grafted activated carbon as inexpensive shale hydration inhibitor. 
Carbohydr Res 491:107960. https://doi.org/10.1016/j.carres. 2020.107960

Mvomo NE, Pingchuan D, Chinedu JO (2021) New EOR technology: simultaneous gas alternating gas (SGAG) injection. In: IOP Conference Series: earth and environmental science, Volume 814, 20215 th International conference on sustainable energy engineering (ICSEE 2021) 3-5 February 2021, Singapore. https://doi.org/ 10.1088/1755-1315/814/1/012006.

Mydland S, Whitson CH, Carlsen ML, Dahouk MM, Ilina Y (2020) Black-Oil and Compositional Reservoir Simulation of Gas-Based EOR in Tight Unconventionals. Paper presented at the SPE/ AAPG/SEG Unconventional Resources Technology Conference, Virtual, https://doi.org/10.15530/urtec-2020-2765

Okere CJ, Su G, Gu X, Han B, Tan C (2021) An integrated numerical visualization teaching approach for an undergraduate course, flow in porous media: an attempt toward sustainable engineering education. Comput Appl Eng Educ. https://doi.org/10.1002/cae.22426

Okere CJ, Su G, Zheng L, Cai Y, Li Z, Liu H (2020) Experimental, algorithmic, and theoretical analyses for selecting an optimal laboratory method to evaluate working fluid damage in coal bed methane reservoirs. Fuel. https://doi.org/10.1016/j.fuel.2020.118513

Okere CJ, Zheng L, Su G, Liu H, Chang Q, Obiafudo OJ (2021) Critical Analysis of productivity of well $2 \mathrm{~L}$ after foam-acid diversion. In: Zheng L, Sun C, Goh KL (eds) Proceedings of MEACM 2020. MEACM 2020. Mechanisms and machine science, Vol 99. Springer, Cham. https://doi.org/10.1007/978-3-030-67958-3_3

Peng DY, Robinson DB (1976) A new two-constant equation of state. Ind Eng Chem Fundam 15(1):59-64. https://doi.org/10.1021/ i160057a011

Phukan R, Gogoi SB, Tiwari P (2019) Enhanced oil recovery by alkaline-surfactant-alternated-gas/CO2 flooding. J Petrol Explor Prod Technol. https://doi.org/10.1007/s13202-018-0465-0

Pourhadi S, Hashemi FA (2020) Performance of the injection of different gases for enhanced oil recovery in a compositionally grading oil reservoir. J Petrol Explor Prod Technol 10:641-661. https:// doi.org/10.1007/s13202-019-0723-9

Runxuan S, Wei Y, Feng X, Hui P, Jijun M (2019) Compositional simulation of $\mathrm{CO} 2$ Huff-n-Puff process in Middle Bakken tight oil reservoirs with hydraulic fractures. Fuel 236:1446-1457. https:// doi.org/10.1016/j.fuel.2018.09.113

Roozbeh R, Hossein H, Ahmad KI, (2012) Application of sustainable foaming agents to control the mobility of carbon dioxide in enhanced oil recovery. In: SPE Kuwait international petroleum conference and exhibition, Kuwait City, Kuwait, Paper Number: SPE-163287-MS. https://doi.org/10.2118/163287-MS

Savjani KT, Gajjar AK, Savjani JK (2012) Drug solubility: importance and enhancement techniques. ISRN Pharm. https://doi.org/ $10.5402 / 2012 / 195727$

Sher E (1998) Environmental aspects of air pollution. In: Handbook of air pollution from internal combustion engines, 1st edition. Academy press, San Diego, New York, pp 27-41

Sikandar K, Orc YK, Abdullatif AS, Salem B, Naveed I (2020) The geomechanical and fault activation modeling during $\mathrm{CO} 2$ injection into deep Minjur reservoir Eastern Saudi Arabia. Sustainability 12(23):9800. https://doi.org/10.3390/su12239800

Sohrabi M, Danesh A, Tehrani DH, Mahmoud J (2008) Microscopic mechanisms of oil recovery by near-miscible gas injection. Transp Porous Med 72:351-367. https://doi.org/10.1007/ s11242-007-9154-z

Subero CL (2009) Numerical modeling of nitrogen injection into gas condensate reservoir. Graduate Thieses, Dissertations, Problem Reports. https://researchrepository.wvu.edu/etd/2021
Tawfik AS (2021) Carbon nanotube-incorporated alumina as a support for MoNi catalysts for the efficient hydrodesulfurization of thiophenes. Chem Eng J 404:126987. https://doi.org/10.1016/j. cej.2020.126987

Tawfik AS (2020) Characterization, determination and elimination technologies for sulfur from petroleum: toward cleaner fuel and a safe environment. Trends Environ Anal Chem. https://doi.org/ 10.1016/j.teac.2020.e00080

Tawfik AS (2021) Protocols for synthesis of nanomaterials, polymers, and green materials as adsorbents for water treatment technologies. Environ Technol Innov 24:101821. https://doi.org/10.1016/j. eti.2021.101821

Tawfik AS, Mukaila AI (2019) Advances in functionalized nanoparticles based drilling inhibitors for oil production. Energy Rep 5:1293-1304. https://doi.org/10.1016/j.egyr.2019.06.002

Tawfik AS, Mukaila AI (2021) Synthesis of amyl ester grafted on carbon-nanopolymer composite as an inhibitor for cleaner shale drilling. Petroleum. https://doi.org/10.1016/j.petlm.2021.07.002

Teletzke G, Patel P, Chen A (2005) Methodology for miscible gas injection EOR screening. SPE international improved oil recovery conference in Asia Pacific, 5-6 December. Malaysia. Society of Petroleum Engineers, Kuala Lumpur, pp 1-11

Vo Thanh H, Sugai Y, Sasaki K (2020) Application of artificial neural network for predicting the performance of $\mathrm{CO} 2$ enhanced oil recovery and storage in residual oil zones. Sci Rep 10(1):18204. https://doi.org/10.1038/s41598-020-73931-2

Wang J, Zhang Y, Xie J (2020) Influencing factors and application prospects of $\mathrm{CO} 2$ flooding in heterogeneous glutenite reservoirs. Sci Rep 10:1839. https://doi.org/10.1038/s41598-020-58792-z

Wei Y, Hamid RL, Kan W, Kamy S (2015) CO2 injection for enhanced oil recovery in Bakken tight oil reservoirs. Fuel 159:354-363. https://doi.org/10.1016/j.fuel.2015.06.092

Xinrui L, Zhongchun L, Jirui H, Tie L (2017) Mechanism and influencing factors of EOR by $\mathrm{N} 2$ injection in fractured-vuggy carbonate reservoirs. J Nat Gas Sci Eng. https://doi.org/10.1016/j.jngse. 2017.02.022

Yong T, Zhengyuan S, Jibo H, Fulin Y (2016) Numerical simulation and optimization of enhanced oil recovery by the in situ generated $\mathrm{CO} 2$ huff-n-puff process with compound surfactant. J Chem. https://doi.org/10.1155/2016/6731848

Yuan Z, Hamid RL, Yuan D, Kamy S (2017) Capillary pressure effect on phase behavior of $\mathrm{CO} 2 /$ hydrocarbons in unconventional reservoirs. Fuel 197:575-582. https://doi.org/10.1016/j.fuel.2017. 02.021

Zendehboudi S, Ahmadi MA, Bahadori A, Shafiei A, Babadagli T (2013) A developed smart technique to predict minimum miscible pressure-eor implications. Can J Chem Eng 91(7):1325-1337. https://doi.org/10.1002/cjce.21802

Zuloaga-Molero P, Yu W, Xu Y, Kamy S, Baozhen L (2016) Simulation study of CO2-EOR in tight oil reservoirs with complex fracture geometries. Sci Rep 6:33445. https://doi.org/10.1038/srep33445

Publisher's Note Springer Nature remains neutral with regard to jurisdictional claims in published maps and institutional affiliations. 